\title{
Research on Identification and Supervision of Ecological Background of Subtropical Mountainous Highways Based on Multi-source Data
}

\author{
ZHAO Ming ${ }^{1}$, HUA Kai-cheng ${ }^{1}$, ZHANG Dong $^{2}$, NI Dong ${ }^{2}$, YUAN Min-min ${ }^{2}$, WANG Zhao-ming ${ }^{2 *}$ \\ ${ }^{1}$ Guangdong Luqiao Construction Development Co., Ltd., Guangzhou, 510623, China. \\ ${ }^{2}$ Research Institute of Highway, Ministry of Transport, Beijing, 100088, China.
}

\begin{abstract}
Based on the UAV remote sensing method combined with multi-source remote sensing data, the ecological background of the subtropical mountainous area was investigated based on the Huizhou to Qingyuan section of the Shantou-Zhanjiang Expressway. Ecological background evaluation indicators are the theoretical basis to support the analysis and evaluation of this article. The ecological indicators of roads in South China have selected five indicators: vegetation cover index, water environment index, soil erosion index, terrain slope index and land use type index.
\end{abstract}

\section{Introduction}

Based on the UAV remote sensing method combined with multi-source remote sensing data, the ecological background of the subtropical mountainous area was investigated based on the Huizhou-Qingyuan section of the Shantou-Zhanjiang Expressway. The ecological background evaluation index is the theoretical foundation that supports the analysis and evaluation of this article. The ecological indicators of roads in South China selected five indicators of vegetation cover index, water environment index, soil erosion index, terrain slope index and land use type index to the ecological background.

\section{Methodology}

(1) Determine the research scope.

The scope of highway ecosystem research is generally considered to be the boundary of highway ecosystems. The boundaries of highway ecosystems are generally ambiguous, because different research objects have different system boundaries. When analysing the microclimate effect of the highway, according to the nature of the underlying surface of the highway, a microclimate zone with temperature, heat, humidity, wind and soil conditions that are different from the surrounding will gradually form around the highway. After a period of evolution, the landscape elements around the highway may have local differences, new biological communities and marginal species appear, and they show a certain degree of transition. This is a feature used to determine the boundary.
The reasonable determination of the boundary of the highway ecosystem is the key to the reasonable evaluation of the highway ecosystem. The boundary of the highway ecosystem is a collection of the boundaries of various other research objects. The boundaries of this set are related to the analysis of various impacts and are a function of the boundaries of other research objects.

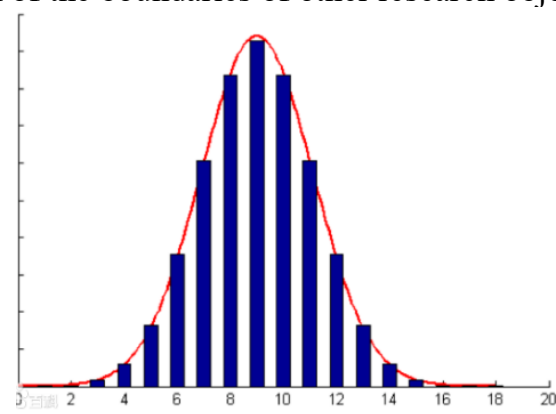

Fig.1 Normal distribution of road ecological range

The format of the terrain raw data mainly includes data, data, etc. Data to generate terrain, because the file format in the data is public, so this article chooses file data to generate terrain grid data.

(2) Investigation and analysis of environmental sensitivity based on spatial relationships

a. Investigation of wild plants and animals and habitats

Investigate wild animal and plant species, protection levels, distribution, living (growth) habits, activity rules, economic and academic value, etc. Investigate the composition of dominant plant communities, vegetation coverage, road land, forest land and grassland area occupied, or the number of felled trees.

b. Investigation of the effects of soil erosion 
The evaluation scope is within the road boundary on both sides of the highway, as well as excavation and spoil grounds; the evaluation content is the slope of high filling and deep excavation in the construction of the road and the spoil (slag) extraction sites, which may easily cause geological diseases such as landslides and debris flows after disturbance Of the road.

Status survey and evaluation: Investigate the current status of soil and water loss along the line, soil erosion types, topography, landforms, geology, vegetation coverage, rainfall, and soil erosion modulus, etc., and comprehensively review the status and management of soil and water control areas in the route landscape area.

c. Investigation of water environmental impact

Investigate the distribution and functional classification of surface waters within the evaluation scope, understand the construction plan of the project, the location and size of the living service area, investigate the surface runoff location and water functions on both sides of the highway construction project, and investigate the existing water pollution discharge sources within the evaluation scope .

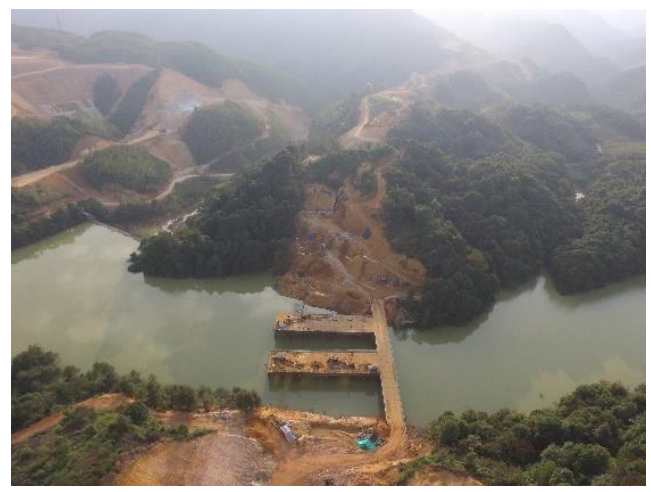

\section{Data analysis}

Because the road ecological evaluation factors involve spatial information such as hydrology, topography, land use, water source and river. GIS is an effective tool for managing the spatial data of road landscape evaluation. GIS has the powerful functions of collecting, storing, updating, retrieving, statistics, mapping, model application and spatial analysis of spatial data of road environment. It can synthesize and store the proposed high-speed different formats, scattered data and image data together, which is convenient for local analysis and overall decision-making, and for checking and updating spatial information, providing data support for ecological evaluation analysis. GIS can build simulation models, and through virtual reality technology, experts can have a comprehensive and in-depth understanding of local conditions. Landscape data is the basis for landscape analysis and evaluation. Traditional methods are obtained through field surveys, surveys, and surveys. For large-scale road ecological analysis and evaluation, the amount of data that needs to be collected and processed is very large, and traditional methods cannot meet the requirements. Remote sensing (RS) technology and GPS are effective methods to solve the problem.

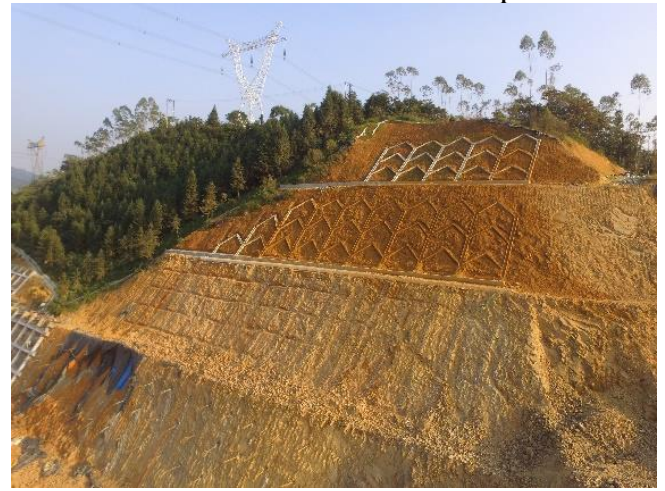

Fig 2. UVA image of highway, 2018.06

\section{Results}

\section{Vegetation coverage factor}

Vegetation coverage is a major indicator of ecosystems, and changes in vegetation coverage over a wide range of ecosystems reflect the effects of human activities on the ecological environment. The subtropical mountainous area has relatively serious damage to the native vegetation, but the vegetation in the Nankunshan Forest Park is relatively intact. Therefore, it has important guiding significance for the ecological route selection of the subtropical mountainous roads by the vegetation type, distribution, and coverage survey team of Huiqing Expressway.

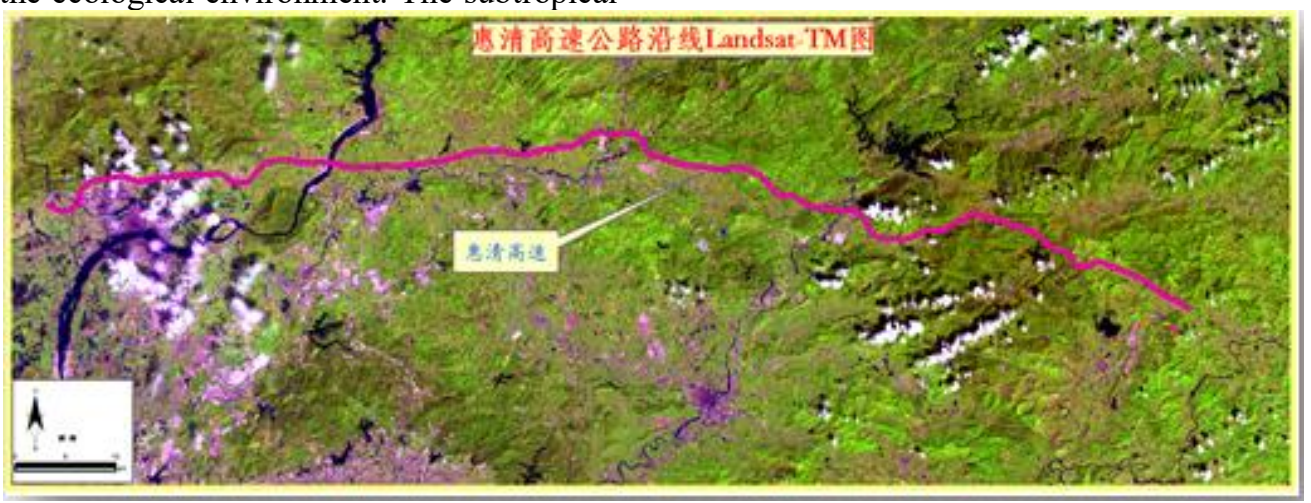

Fig.3 Landsat-TM remote sensing image map along Huiqing highway 


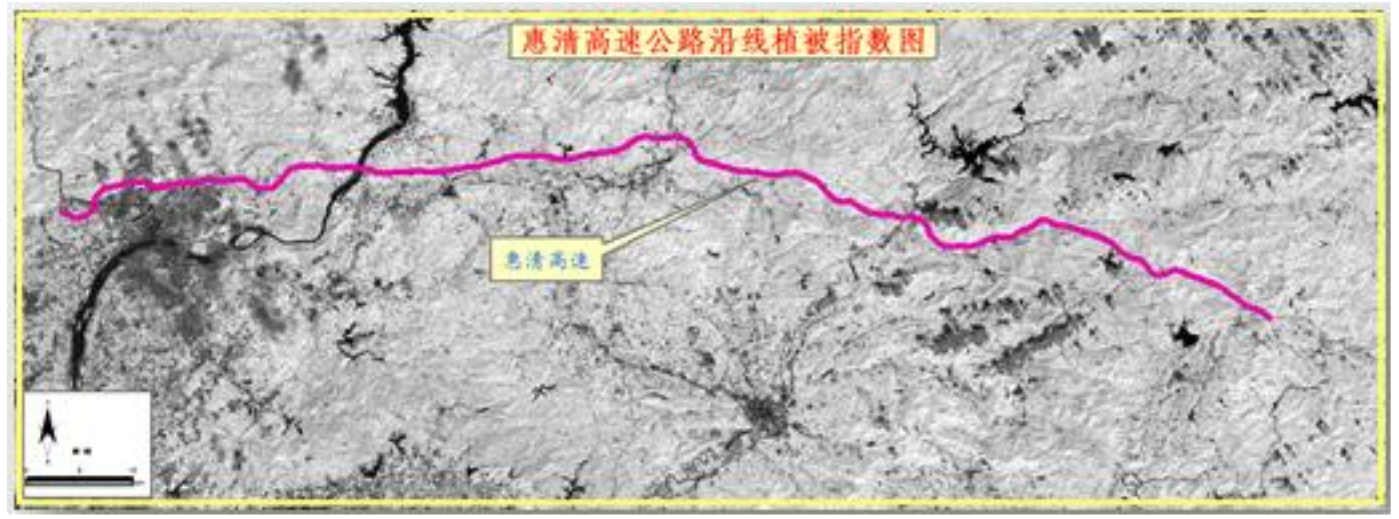

Fig.4 Vegetation Index of Huiqing highway

\section{The water environment}

The water environment is mainly composed of surface water environment and groundwater environment. Water environmental damage is a major aspect of environmental damage in subtropical mountains caused by road construction. The types of subtropical mountainous areas are complex and diverse, with abundant surface water and frequent exchange with groundwater. At the same time, agricultural irrigation systems are complex, so road construction can easily cause damage and pollution to surface water, groundwater and irrigation systems.

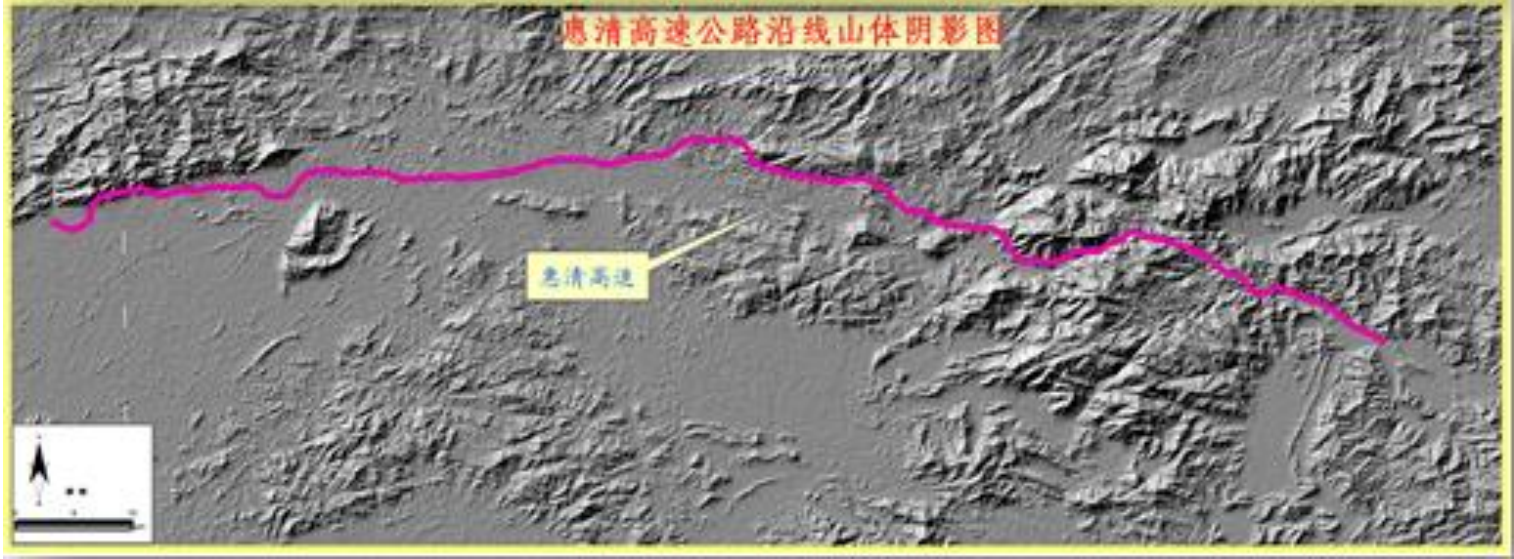

Fig.5. Shadow map of mountains along Huiqing highway

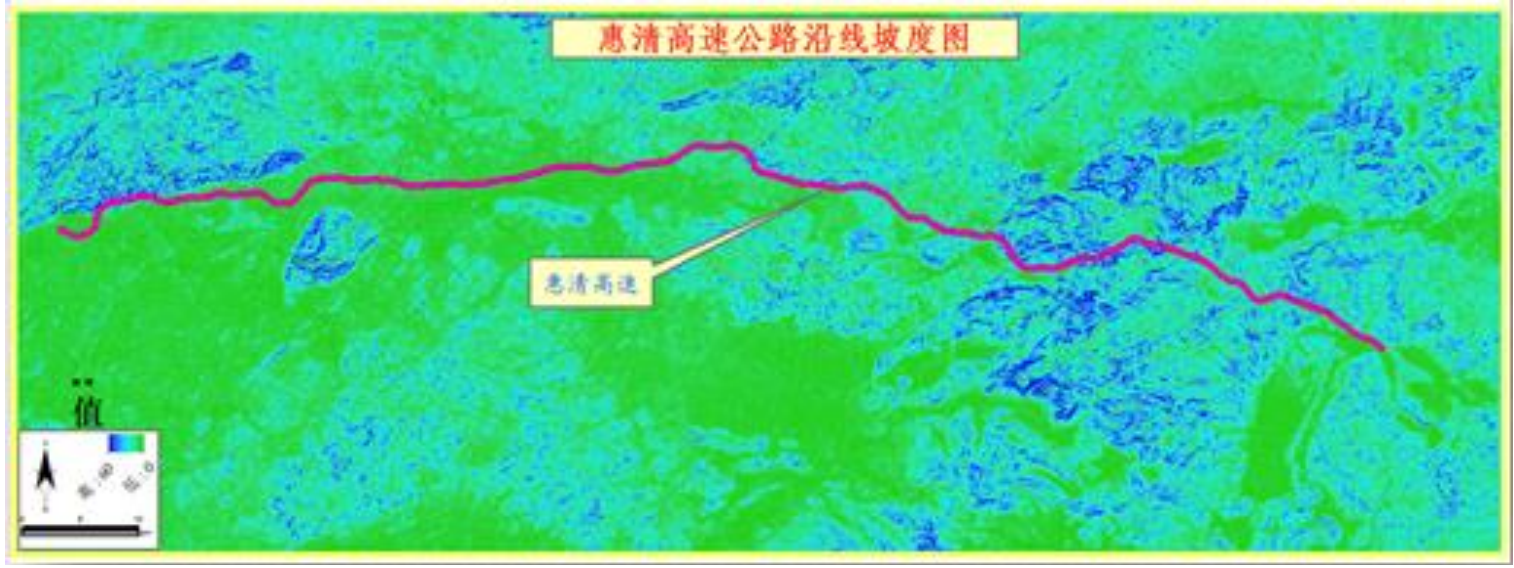

Fig.6.Slope map along Huiqing highway

Terrain Slope Factor

Terrain slope is the main morphological index reflecting terrain. The terrain slope will have an important impact on route selection, construction, maintenance, and operation of highways, and various road disasters are related to terrain and landforms.
To some extent, it reflects the interference of human activities on the subtropical mountain ecosystem, and directly affects the structure and functional succession of the subtropical mountain ecological environment. At the same time, land use types are also important reference factors for highway design, construction, and maintenance. 


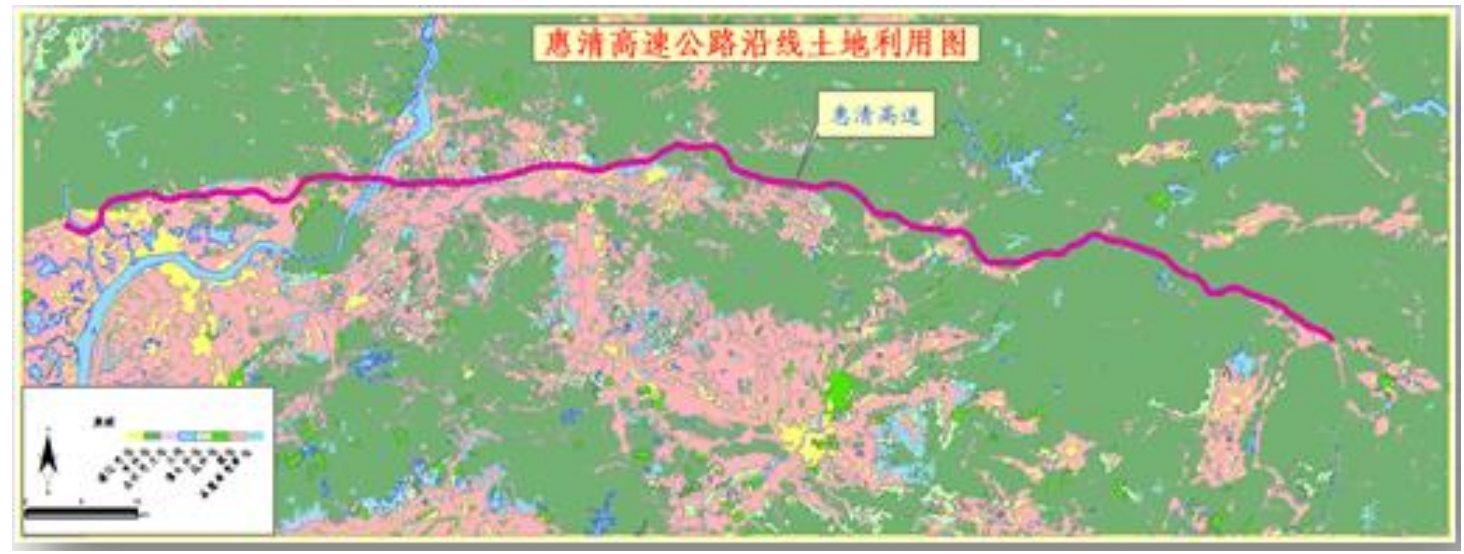

Fig.7 Landuse of Huiqing highway

Due to the slow soil formation speed and strong soil erosion in the subtropical mountainous areas, and the soil piled up during the construction and operation of the highway, construction wasteland, construction waste and domestic garbage, etc., will disturb the soil in the road area, disturb the original soil development level and soil Body configuration, destroying the original soil structure, texture and other soil properties.

\section{Conclusion}

This study is using Landsat, GF-1, GF-2, and QuickBird high-resolution remote sensing images. We carry out sample surveys, and investigate the plant species height, species, height in the sample, cover, frequency, etc. The authors record the latitude, longitude, and elevation of the plot.

\section{References}

1. Shine R, Lemaster M, Wall M, et a1. Why Did the Snake Cross the Roads? Effects of Roads on Movement and Location of Mates by Garter Snakes [J]. Ecology and Society, 2004, 9(1): 9.

2. Eaglin G S, Hubert W A. Management Briefs: Effects of Logging Roads on Substrate and Trout in Streams of the Medicine Bow National Forest, Wyoming[J]. North American Journal of Fisheries Management, 1993, (13): 844-846.

3. Mcharg I L. Design with Nature[M]. New York: Natural History Press, 1969.

4. Steinitz C, Parker P, Jordan L. Hand- Drawn Overlays: Their History and Prospective uses[J]. Landscape Architect, 1976, 66(5): 444-445. 